\title{
BERKACA NU DAN MUHAMMADIYAH DALAM MEWUJUDKAN NILAI-NILAI MODERASI ISLAM DI INDONESIA
}

\author{
Amru Almu'tasim \\ Fakultas Tarbiyah Institut Agama Islam Uluwiyah Mojokerto \\ Email :amru.dosen@yahoo.com
}

\begin{abstract}
Maintaining the moderation of Islam in Indonesia is a must because it is a command of the Qur'an. Didin Hafidhuddin said; Moderate does not mean that all religions are equal in line with the Ministry of Religion and MUI. Collaborative Cadre of Moderate Missionaries Muhammadiyah moderate and not excessive "Not too right (extreme) and not too left (liberal). This group of moderate wasathons or Muslims, in Ahlussunnah wal Jamaah (Aswaja) terms are called sawadh al-a'zham, or the largest group, the Aswaja group. It is this group that is embraced by most Muslims in Indonesia, which has so far maintained the country's sovereignty. The trend that is being echoed in the world today is the enthusiasm of Muslims to maintain this moderation, namely moderate Islam. So it is important, because it is too right (extreme) to only see things from a black and white, halal and haram angle, which sometimes when applied in a pluralistic society is not quite right, "sure the goals of all Islamic groups in Indonesia are the same, but when delivered in a way right and more flexible, it is felt to have more impact compared to the extreme values of moderation of Islam that is actually what is currently needed by the world and needs to be used as a reference for sawad al-a'zham or the Muslim group, Aswaja and this is very in accordance with The Koran commands The problem is that there are opinions of Muslims who think that if there is something that is not in accordance with Islam, everything needs to be replaced, even though there are principles of figh that view the business and its way, as long as the benefits for Muslims must be accepted.
\end{abstract}

Key word: Islamic moderation, NU and Muhammadiyah, Indonesia

\section{PENDAHULUAN}

Fakta moderasi Islam itu dibentuk oleh pergulatan sejarah Islam Indonesia yang cukup panjang. NU dan Muhammadiyah adalah dua organisasi Islam yang sudah malang-melintang dalam memperjuangkan bentuk-bentuk moderasi Islam, baik lewat institusi pendidikan yang mereka kelola maupun kiprah sosial-politik- keagamaan yang dimainkan. Oleh karena itu, kedua organisasi ini patut disebut sebagai dua institusi civil society yang amat penting bagi proses moderasi negeri ini. NU dan Muhammadiyah merupakan dua organisasi sosial-keagamaan yang berperan aktif dalam merawat dan menguatkan jaringan dan institusi-insitusi penyangga moderasi Islam, bahkan 
menjadikan Indonesia sebagai proyek percontohan toleransi bagi dunia luar. Dikatakan pula, sebagai organisasi Islam terbesar di Indonesia, NU selama ini memainkan peran yang signifikan dalam mengusung ide-ide keislaman yang toleran dan damai ${ }^{1}$.

Muhammadiyah, misalnya, adalah suatu pergerakan sosial- keagamaan modern yang bertujuan untuk mengadaptasikan ajaran- ajaran Islam yang murni ke dalam kehidupan dunia modern Indonesia. Dalam usaha mencapai tujuan tersebut, gerakan ini secara luas telah mendapatkan inspirasi dari ide- ide pembaruan Syaikh Muhammad Abduh, yang mengobarkan semangat pembaruan pembersihan Islam dari daki-daki sejarah yang selama ini dianggap bagian tak terpisahkan dari Islam².

Dalam sejarah kolonialisme di Indonesia, Muhammadiyah dapat disebut moderat, karena lebih menggunakan pendekatan pendidikan dan transformasi budaya. Karakter gerakan Muhammadiyah terlihat sangat moderat, terlebih jika dibandingkan dengan gerakan Islam yang menggunakan kekerasan dalam perjuangan mengusir penjajah, sebagaimana ditunjukkan oleh gerakan-gerakan kelompok tarekat yang melakukan pemberontakan dengan kekerasan. Dalam perjalanan sejarah selanjutnya, NU dan Muhammadiyah adalah organisasi Islam yang paling produktif membangun dialog di kalangan internal masyarakat Islam, dengan tujuan membendung gelombang radikalisme. Dengan demikian, agenda Islam moderat tidak bisa dilepas dari upaya membangun kesalingpahaman (mutual understanding) antar peradaban ${ }^{3}$.

\section{PEMBAHASAN}

Moderasi Islam dalam bahasa arab disebut dengan al-Wasathiyyah alIslamiyyah. Al-Qardawi menyebut beberapa kosakata yang serupa makna dengannya termasuk katan Tawazun, I'tidal, Ta'adul dan Istiqamah. Sementara dalam bahasa inggris sebagai Islamic Moderation. Moderasi Islam adalah sebuah pandangan atau sikap yang selalu berusaha mengambil posisi tengah dari dua sikap yang berseberangan dan berlebihan sehingga salah satu dari kedua sikap yang dimaksud tidak mendominasi dalam pikiran dan sikap seseorang. Dengan kata lain seorang Muslim moderat adalah Muslim yang memberi setiap nilai atau aspek yang berseberangan bagian tertentu tidak lebih dari porsi yang semestinya. Adapun istilah

\footnotetext{
${ }^{1}$ Ahmad Zainul Hamid. "NU dalam Persinggungan Ideologi: Menimbang Ulng Moderasi Keislaman Nahdatul Ulama”. Afkar, Edisi No. 21 Tahun 2007, hal. 28

2 Alwi Shihab, Membendung Arus: Respons Gerakan Muhammadiyah terhadap Penetrasi Misi Kristen di Indonesia, Jakarta: Mizan, 1998. hal.303-304

${ }^{3}$ M. Hilaly Basya, "Menelusuri Artikulasi Islam Moderat di Indonesia", http://www.madinask.com. diakses tanggal 19 Agustus 2019.
} 
moderasi menurut Khaled Abou el Fadl dalam The Great Theft adalah paham yang mengambil jalan tengah, yaitu paham yang tidak ekstem kanan dan tidak pula ekstrem $\mathrm{kiri}^{4}$.

K.H. Abdurrahman Wahid pun merumuskan bahwa moderasi harus senantiasa mendorong upaya untuk mewujudkan keadilan sosial yang dalam agama dikenal dengan al-maslahah al-'ammah. Bagaimanapun hal ini harus dijadikan sebagai fondasi kebijakan publik, karena dengan cara yang demikian itu kita betul-betul menerjemahkan esensi agama dalam ruang publik. Dan setiap pemimpin mempunyai tanggungjawab moral yang tinggi untuk menerjemahkannya dalam kehidupan nyata yang benar-benar dirasakan oleh publik $^{5}$. Islam selalu bersikap moderat dalam menyikapi setiap persoalan, bahkan prinsip moderasi ini menjadi karakteristik Islam dalam merespon segala persoalaan.

Dalam konteks keseimbangan, Rasulullah pun melarang umatnya untuk tidak terlalu berlebihan meski dalam menjalankan agama sekalipun. Beliau lebih senang jika hal itu dilakukan secara wajar tanpa adanya pemaksaan diri dari yang berlebihan. Sedangkan dalam realitas kehidupan nyata, manusia tidak dapat menghindarkan diri dari perkara-perkara yang berseberangan. Karena itu al-Wasathiyyah Islamiyyah mengapresiasi unsur rabbaniyyah (ketuhanan) dan Insaniyyah (kemanusiaan), mengkombinasi antara Maddiyyah (materialisme) dan ruhiyyah (spiritualisme), menggabungkan antara wahyu (revelation) dan akal (reason), antara maslahah ammah (al-jamāiyyah) dan maslahah individu (al-fardiyyah).

Beberapa gambaran keseimbangan inilah yang biasa dikenal dengan istilah "moderasi". Kata moderasi sendiri berasal dari bahasa inggris, moderation, yang artinya adalah sikap sedang atau sikap tidak berlebihan. Jika dikatakan orang itu bersikap moderat berarti ia wajar, biasa-biasa saja, dan tidak ekstrim. Sementara dalam bahasa arab, kata moderasi biasa diistilahkan dengan wasat atau wasatiyah; orangnya disebut wasit. Kata wasit sendiri sudah diserap ke dalam bahasa Indonesi yang memiliki tiga pengertian, yaitu 1) penengah, pengantara (misalnya dalam perdagangan, bisnis, dan sebagainya), 2) pelerai (pemisah, pendamai) antara yang berselisih, dan 3) pemimpin di pertandingan. Yang jelas, menurut pakar bahasa arab, kata tersebut merupakan "segala yang baik sesuai objeknya". Dalam sebuah ungkapan bahasa Arab disebutkan (sebaik-baik segala sesuatu adalah yang berada di

${ }^{4}$ Zuhairi Misrawi, Hadratussyaikh Hasyim Asy'ari Moderasi, Keutamaan, dan Kebangsaan (Jakarta: PT Kompas Media Nusantara, 2010), hal.13

5 lbid, hal.14 
tengah-tengah. Misalnya dermawan yaitu sikap di antara kikir dan boros, pemberani yaitu sikap di antara penakut dan nekat, dan lain-lain ${ }^{6}$.

\section{Bentuk Moderasi Muhammadiyah dan NU}

Sikap moderasi Muhammadiyah sebenarnya sejak awal telah dibangun oleh pendiri organisasi ini, yaitu K.H. Ahmad Dahlan. Dikatakan, salah satu pelajaran yang paling penting dari kepemimpinan Ahmad Dahlan adalah komitmen kuatnya kepada sikap moderat dan toleransi beragama. Selama kepemimpinannya dapat terlihat adanya kerja sama kreatif dan harmonis dengan hampir semua kelompok masyarakat. Bahkan, dengan rekan Kristennya, beliau mampu mengilhami rasa hormat dan kekaguman. Contoh yang paling menarik dari kemampuan K.H. Ahmad Dahlan adalah mengikat persahabatan erat dengan banyak pemuka agama Kristen. Kenyataan bahwa beliau dikenal sebagai orang yang toleran terhadap kaum misionaris Kristen akan tetapi tidak berarti lantas beliau mengkompromikan prinsip- prinsipnya. Dia adalah seorang praktisi dialog antaragama yang sejati, dalam pengertian dia mendengar apa yang dikatakan dan memerhatikan apa yang tersirat di balik kata yang diucapkan7. Dalam perkembangan lebih lanjut, Syafi'i mencatat, bahwa:

"Gerakan modernis itu, terutama Muhammadiyah semakin mempertimbangkan dimensi kultural dalam gerak dakwahnya sehingga terasa menjadi lebih lentur tanpa kehilangan prinsip dan misi utamanya. Persis dan Al- Irsyad tetap bertahan, tetapi tidak pernah mengikuti mitranya Muhammadiyah yang terus berekspansi"8.

Sementara itu, sikap moderasi NU pada dasarnya tidak terlepas dari akidah Ahlusunnah waljama'ah (Aswaja) yang dapat digolongkan paham moderat. Dalam Anggaran Dasar NU dikatakan, bahwa NU sebagai Jam'iyah Diniyah Islamiyah berakidah Islam menurut paham Ahlussunah waljamaah dengan mengakui mazhab empat, yaitu Hanafi, Maliki, Syafi'i, dan Hambali. Penjabaran secara terperinci, bahwa dalam bidang akidah, NU mengikuti paham Ahlussunah waljamaah yang dipelopori oleh Imam Abu Hasan al- Asy'ari, dan Imam Abu Mansyur al- Maturidi. Dalam bidang fikih, NU mengikuti jalan pendekatan (al- mazhab) dari Mazhab Abu Hanifah alNu'man, Imam Malik ibn Anas, Imam Muhammad ibn Idris al-Syafi'i, dan Ahmad ibn

${ }^{6}$ Departemen Agama RI, Moderasi Islam (Jakarta: Lajnah Pentashihan Mushaf AI-Qur'an, 2012), hal.

7 Alwi Shihab, Membendung Arus: Respons Gerakan Muhammadiyah terhadap Penetrasi Misi Kristen di Indonesia, Jakarta: Mizan, 1998. hal. 311-312

8 lbid, hal. 60 
Hanbali. Dalam bidang tasawuf mengikuti antara lain Imam Junaid al-Bagdadi dan Imam Ghazali, serta imam-imam yang lain ${ }^{9}$.

Perkataan Ahlusunnah waljama'ah dapat diartikan sebagai "para pengikut tradisi Nabi Muhammad SAW dan ijmak (kesepakatan) ulama". Sementara itu, watak moderat (tawassuth) merupakan ciri Ahlussunah waljamaah yang paling menonjol, di samping juga i'tidal (bersikap adil), tawazun (bersikap seimbang), dan tasamuh (bersikap toleran), sehingga ia menolak segala bentuk tindakan dan pemikiran yag ekstrem (tatharruf) yang dapat melahirkan penyimpangan dan penyelewengan dari ajaran Islam. Dalam pemikiran keagamaan, juga dikembangkan keseimbangan (jalan tengah) antara penggunaan wahyu (naqliyah) dan rasio ('aqliyah) sehingga dimungkinkan dapat terjadi akomodatif terhadap perubahan- perubahan di masyarakat sepanjang tidak melawan doktrin-doktrin yang dogmatis. Masih sebagai konsekuensinya terhadap sikap moderat, Ahlussunah waljamaah juga memiliki sikapsikap yang lebih toleran terhadap tradisi dibanding dengan paham kelompok-kelompok Islam lainnya. Bagi Ahlussunah, mempertahankan tradisi memiliki makna penting dalam kehidupan keagamaan. Suatu tradisi tidak langsung dihapus seluruhnya, juga tidak diterima seluruhnya, tetapi berusaha secara bertahap di-Islamisasi ${ }^{10}$.

Pemikiran Aswaja sangat toleransi terhadap pluralisme pemikiran. Berbagai pikiran yang tumbuh dalam masyarakat muslim mendapatkan pengakuan yang apresiatif. Dalam hal ini Aswaja sangat responsif terhadap hasil pemikiran berbagai mazhab, bukan saja yang masih eksis di tengah- tengah masyarakat (Mazhab Hanafi, Malik, Syafi'i, dan Hambali), melainkan juga terhadap mazhab- mazhab yang lain seperti imam Daud al-Zhahiri, Imam Abdurrahman al-Auza'i, Imam Sufyan al- Tsauri, dan lain-lain ${ }^{11}$.

Model keberagamaan NU, sebagaimana disebutkan, mungkin tepat apabila dikatakan sebagai pewaris para wali di Indonesia. Diketahui, usaha para wali untuk menggunakan berbagai unsur non- Islam merupakan suatu pendekatan yang bijak. Bukankah Alquran menganjurkan sebuah metode yang bijaksana ${ }^{12}$, yaitu;

Serulah (manusia) kepada jalan Tuhan-mu dengan hikmah dan pelajaran yang baik dan bantahlah mereka dengan cara yang baik. Sesungguhnya Tuhanmu Dialah yang lebih mengetahui tentang siapa yang tersesat dari

\footnotetext{
9 Mujamil Qomar, NU Liberal; Dari Tradisionalisme Ahlusunnah ke Universalisme Islam, Bandung: Mizan, 2002. hal.62

10 Zamakhsyari Dhofier,Tradisi Pesantren; Studi Tentang Pandangan Hidup Kiai, Jakarta: LP3ES, 1994. hal. 148

11 Muhammad Mihanna, Al-Irhāb wa Azmat al-Qānūn al-Dauly al- Mu'āshir, dalam Al-Islām fi Muwājahat al-Irhābi, Cairo: Rābithah al-Jāmi'at al- Islāmiyah, 2003.

12 Abdurrahman Mas'ud, (2006), "Dari Haramain ke Nusantara : Jejak Intelektual Arsitek Pesantren", Jakarta: Kencana. hal. 9
} 
jalan-Nya dan Dialah yang lebih mengetahui orang-orang yang mendapat petunjuk. $^{13}$

Dalam mendinamiskan perkembangan masyarakat, kalangan NU selalu menghargai budaya dan tradisi lokal. Metode mereka sesuai dengan ajaran Islam yang lebih toleran pada budaya lokal. Hal yang sama merupakan cara-cara persuasif yang dikembangkan Walisongo dalam mengislamkan pulau Jawa dan menggantikan kekuatan Hindu-Budha pada abad XVI dan XVII. Apa yang terjadi bukanlah sebuah intervensi, tetapi lebih merupakan sebuah akulturasi hidup berdampingan secara damai. Ini merupakan sebuah ekspresi dari "Islam kultural" atau "Islam moderat" yang di dalamnya ulama berperan sebagai agen perubahan sosial yang dipahami secara luas telah memelihara dan menghargai tradisi lokal dengan cara mensubordinasi budaya tersebut ke dalam nilai-nilai Islam ${ }^{14}$.

Moderasi Islam adalah jalan tengah di tengah keberagaman beragama. Wajah moderasi Islam nampak dalam hubungan harmoni antara Islam dan kearifan lokal (local value). Kearifan lokal ini sebagai warisan budaya Nusantara, mampu disandingkan secara sejajar sehingga antara spirit islam dan kearifan budaya berjalan seiring, tidak saling menegasikan. Di sinilah wajah Islam Indonesia dipandang sangat tepat diterapkan dalam konteks heterogenitas budaya di kawasan ASEAN maupun dunia ${ }^{15}$.

Moderasi Islam juga berperan besar dalam mendialogkan Islam dan modernitas. Terhadap modernitas, Islam tidak dalam posisi menolak atau menerima secara menyeluruh, melainkan tetap mengedepankan sikap kritis sehingga modernitas tumbuh menjadi nilai positif ketimbang negatil. Di saat negara-negara muslim begitu kaku dan konservatif terhadap perubahan dan produk-produk modernitas, Indonesia justru menjadikannya media dakwah dengan memasukan spirit Islam di dalamnya. Kini, di saat dunia terus berada dalam bayang-bayang benturan sosial, seperti yang terjadi di Afghanistan, Irak, Suriah, hingga Irlandia, Indonesia tampil dengan kebersamaan dalam keragaman. Sungguh sangat indah menyaksikan berbagai agama, budaya, dan suku hidup berdampingan, saling menghormati. Masing-masing daerah tidak lagi mengusung aura kedaerahan atau kesukuan, melainkan hidup rukun di bawah payung Pancasila dalam bingkai NKRI.

13 QS. An Nahl. 125

$14 \mathrm{lbid}$, hal. 10

15 Kementerian Agama, Radikalisme Agam dan Tantangan Kebangsaan, Jakarta: Dirjen Bimbingan Masyarakat Islam, 2014. hal. 65 


\section{Mewujudkan Nilai-nilai Moderasi Islam di Indonesia}

Dalam mewujudkan nilai-nilai moderasi Islam, tentunya dituntut memiliki sikap yang luwes dalam berinteraksi dengan rekan-rekan yang berbeda keyakinan agar tidak menimbulkan ketersinggungan, sikap inilah yang harus ditanamkan pula kepada siapapun dan bagaimana menjadi seorang Muslim yang moderat, tidak liberal dan juga tidak radikal. Sejalan dengan pernyataan Indonesia sebagai negerinya Islam moderat, sebagai role model bagi Negara-negara Muslim lainnya ${ }^{16}$.

Agama Islam adalah agama samawi terakhir yang diturunkan Allah SWT melalui Nabi Muhammad SAW, Islam dipersepsikan mengandung ajaran-ajaran moderat di dalamnya. Disebutkan dalam ayat AI-Quran umat Islam disebut sebagai umatan wasthan, yaitu umat moderat yang tidak ekstrem kanan maupun ekstrem kiri yang berbunyi:

"Dan demikian (pula) Kami telah menjadikan kamu (umat Islam), umat yang adil dan pilihan agar kamu menjadi saksi atas (perbuatan) manusia dan agar Rasul (Muhammad) menjadi saksi atas (perbuatan) kamu". ${ }^{17}$

Wasathiyyah memiliki makna jalan tengah atau keseimbangan antara dua hal yang berbeda atau berkebalikan, seperti keseimbangan antara ruh dan jasad, antara dunia dan akhirat, antara individu dan masyarakat, antara idealitas dan realitas, antara yang baru dan yang lama, antara 'aql dan naql, antara ilmu dan amal, antara usûl dan furû, antara sarana dan tujuan, antara optimis dan pesimis dan seterusnya ${ }^{18}$. Jalan tengah antara dua hal yang berbeda, misalnya antara $A$ dan $B$ mengandung dua pengertian. Pertama, berarti bukan A dan bukan B, contohnya konsep Islam tentang paham adalah jalan tengah diantara liberalisme dan konservatifisme. Hal ini bermakna bahwa Islam tidak konservatif dan tidak juga liberalis. Kedua, berarti bukan hanya $A$ dan bukan hanya B, misalnya Islam itu antara rohani dan jasmani. Maknanya, Islam tidak hanya mengurusi masalah yang bersifat rohani atau jasmani saja akan tetapi mengurusi keduanya secara bersama-sama. ${ }^{19}$

Dengan demikian, yang dimaksud dengan moderasi adalah setiap pola berfikir, pola bertindak, dan berperilaku yang memiliki ciri-ciri tawassuth, tawazun, dan taadul. Watak Wasathiyyah melekat dengan Islam semenjak agama ini lahir, dan In sya Allah

\footnotetext{
${ }^{16}$ Hairul Puadi, "Islam Moderat Dalam Konteks Sosial Politik di Indonesia", dalam Jurnal Pusaka, Edisi Juli-Desember 2014 (Malang: STAI AI-Qolam Gondanglegi), 6-7.

17 QS. Al Baqarah:143

18 Rusmayani, Penanaman Nilai-Nilai Moderasi Islam Siswa Di Sekolah Umum, Proceedings AnCOMS Kopertais Wil 4 Surabaya 21-22 April 2018, hal. 790

$19 \mathrm{lbid}$, Rusmayani, hal. 790
} 
akan terus melekat sampai hari kiamat nanti. Penanaman adalah proses, perbuatan dan cara menanamkan ${ }^{20}$, sedangkan arti nilai adalah suatu perangkat keyakinan atau perasaan yang diyakini sebagai identitas yang memberikan ciri khusus pada pemikiran, perasaan, kriteria maupun perilaku²1.

Wujud nilai adalah suatu tindakan, perilaku atau proses menanamkan suatu tipe kepercayaan yang berada dalam ruang lingkup sistem kepercayaan dimana seseorang bertindak atau menghindari suatu tindakan, atau mengenai sesuatu yang pantas atau tidak pantas dikerjakan ${ }^{22}$. Penanaman nilai-nilai moderasi islam secara umum adalah suatu proses berupa kegiatan atau usaha yang dilakukan dengan sadar, terencana, dan dapat dipertanggungjawabkan untuk memelihara, melatih, membimbing, mengarahkan, dan meningkatkan pengetahuan keagamaan, kecakapan sosial, dan praktek serta sikap keagamaan anak (aqidah/tauhid, ibadah dan akhlak) yang memiliki ciri-ciri tawassuth, tawazun, dan ta'adul atau bisa disatukan menjadi wasathiyyah (keseimbangan antara dua hal yang berbeda), selanjutnya untuk dapat diamalkan dalam kehidupan sehari-hari²3.

Adapun wujud nilai-nilai agama yang harus ditanamkan kepada masyarakat meliputi: 1) Nilai keimanan, 2) Nilai ibadah, dan 3) Nilai akhlak, ada beberapa dasar dalam pendidikan akhlak yang perlu diterapkan, diantaranya adalah; ${ }^{24}$ a) Menanamkan kepercayaan kepada msyarakat yang mencakup percaya pada diri sendiri, percaya pada orang lain terutama dengan pendidikannya, dan percaya bahwa manusia bertanggungjawab atas perbuatan dan perilakunya. la juga mempunyai citacita dan semangat, b) Menanamkan rasa cinta dan kasih terhadap sesama, anggota keluarga, dan orang lain, c) Menyadarkan anak bahwa nilai-nilai akhlak muncul dari dalam diri manusia, dan bukan berasal dari peraturan dan undang-undang. Karena akhlak adalah nilai-nilai yang membedakan manusia dari binatang. d) Menanamkan perasaan peka terhadap toleransi. Caranya adalah membangkitkan perasaan masyarakat terhadap sisi kemanusiaannya, e) Membudayakan akhlak toleran sehingga akan menjadi kebiasaan dan watak pada diri mereka.

Dalam prinsip ajaran Islam, tidak boleh adanya pemaksaan dan apa lagi pencaplokan, sebaliknya jika umat Islam dalam kondisi tertindas maka dalam kondisi

\footnotetext{
20 DepDikBud, Kamus Besar Bahasa Indonesia, ( Jakarta: Balai Pustaka, 1990), 895.

21 Zakiyah Daradjat, IImu Jiwa Agama, ( Jakarta: Bulan Bintang, 1996), 59.

22 Chabib Thoha, Kapita Selekta Pendidikan Islam, (Yogyakarta: Pustaka Pelajar, 2000), 61.

${ }^{23}$ Rusmayani, Penanaman Nilai-Nilai Moderasi Islam Siswa Di Sekolah Umum, Proceedings AnCOMS Kopertais Wil 4 Surabaya 21-22 April 2018, hal. 790

24 Syekh Khalid bin Abdurrahman, Cara Islam Mendidik Anak, (Yogyakarta: ad-Dawa 2006)
} 
ini mempertahankan hak dan kedaulatan menjadi alternatif penyelesaian, sesuai dalam ayat yang berbunyi:

"Oleh sebab itu barangsiapa yang menyerang kamu, maka seranglah ia, seimbang dengan serangannya terhadapmu. Bertakwalah kepada Allah dan ketahuilah, bahwa Allah beserta orang-orang yang bertakwa"25

Dari penjabaran di atas jelas bahwa Islam adalah adalah agama damai dan dakwah yang sangat menjunjung tinggi kebebasan yang bertanggungjawab. Cerminan lain wujud kebebasan memeluk agama adalah bahwa Islam mengayomi secara penuh hak-hak kaum dzimmi, yakni nonmuslim yang mengadakan perjanjian damai di wilayah kekuasaan umat Islam ${ }^{26}$, hal ini tertuang dalam ayat yang berbunyi :

"Allah tidak melarang kalian untuk berbuat baik dan berlaku adil terhadap orang-orang yang tiada memerangi kalian karena agama dan tidak mengusir kalian dari negeri kalian, sesungguhnya Allah menyukai orangorang yang berlaku adil"27

Berlandaskan alqur'an di atas menunjukkan wujud nilai-nilai moderasi di Indonesia harus dikemas dengan sikap toleran antar pemeluk beragama, bukan bersikap superior atau bahkan memandang salah pemeluk agama lain dan merasa paling benar atas jalan keyakinannya.

\section{Sikap Moderasi Islam Perpektif NU dan Muhammadiyah}

\section{Sikap Moderat Perspektif NU}

Mengacu dalam buku Moderasi Islam, setidaknya ada enam ciri-ciri bersikap moderat dalam berislam. Pertama, memahami realitas. Dikemukakan bahwa Islam itu relevan untuk setiap zaman dan waktu (shalih li kulli zaman wa makan). Disebutkan juga bahwa ajaran Islam itu ada yang tetap dan tidak bisa dirubah-seperti shalat lima waktu, dan ada juga yang bisa dirubah karena waktu dan tempat-seperti zakat fitrah dengan beras, gandum, atau sagu tergantung yang menjadi makanan pokok pada masyarakat itu.

Umat Islam yang bersikap moderat (wasath) adalah mereka yang mampu membaca dan memahami realitas yang ada. Tidak gegabah atau ceroboh. Mempertimbangkan segala sesuatu, termasuk kebaikan dan keburukannya.

Terkait hal ini kita bisa belajar banyak dari Nabi Muhammad saw. Beliau adalah orang pandai dalam membaca realitas. Salah satu contohnya adalah Nabi Muhammad

\footnotetext{
${ }^{25}$ QS. Al-Baqarah: 194

${ }^{26}$ Abu Yasid, Islam Moderat, , 46-47.

${ }^{27}$ QS. Al-Mumtahanah: 8
} 
saw. tidak menghancurkan patung-patung yang ada di sekitar Ka'bah selama beliau berdakwah di sana. Beliau sadar tidak memiliki kekuatan untuk melakukannya pada waktu itu. Namun pada saat Fathu Makkah, semua patung dan kemusyrikan di kota Makkah dihancurkan semua.

Kedua, memahami fiqih prioritas. Umat Islam yang bersikap moderat sudah semestinya mampu memahami mana-mana saja ajaran Islam yang wajib, sunnah, mubah, makruh, dan haram. Mana yang fardlu 'ain (kewajiban individual) dan mana yang fardlu kifayah (kewajiban komunal). Di samping memahami mana yang dasar atau pokok (ushul) dan mana yang cabang (furu).

Ketiga, memberikan kemudahan kepada orang lain dalam beragama. Ada istilah bahwa agama itu mudah, tapi jangan dipermudah. Pada saat mengutus Muadz bin Jabal dan Abu Musa al-Asy'ari ke Yaman untuk berdakwah, Nabi Muhammad saw. berpesan agar keduanya memberikan kemudahan dan tidak mempersulit masyarakat setempat.

Cerita lain, pada suatu ketika ada sahabat nabi yang berhubungan badan dengan istrinya pada siang bulan Ramadhan. Lalu sahabat tersebut mendatangi Nabi Muhammad saw. untuk meminta solusi. Nabi Muhammad saw. menyebutkan kalau hukuman dari perbuatan sahabatnya itu adalah memerdekakan budak, puasa dua bulan berturut-turut, atau memberi makan 60 orang fakir miskin. Ternyata sahabat tadi mengaku tidak mampu untuk menjalankan itu semua karena dia memang miskin dan payah. Seketika sahabat tadi membawa sekeranjang kurma untuk nabi. Kemudian Nabi Muhammad saw. menyuruh sahabatnya itu untuk menyedekahkan kurma kepada orang yang paling miskin. Sahabat tadi menjawab kalau dirinya lah orang yang paling miskin. Lalu Nabi Muhammad saw. memerintahkan sahabat tadi untuk membawa sekeranjang kurma itu dan menyedekahkan kepada keluarganya sebagai kafarat atas perbuatannya, jima' pada siang bulan Ramadhan.

Keempat, memahami teks keagamaan secara komprehensif. Perlu dipahami bahwa satu teks dengan yang lainnya itu saling terkait, terutama teks-teks tentang jihad misalnya. Ini yang biasanya dipahami separuh-separuh, tidak utuh, sehingga jihad hanya diartikan perang saja. Padahal makna jihad sangat beragam sesuai dengan konteksnya.

Kelima, bersikap toleran. Umat Islam yang bersikap moderat adalah mereka yang bersikap toleran, menghargai pendapat lain yang berbeda -selama pendapat tersebut tidak sampai pada jalur penyimpangan. Karena sesungguhnya perbedaan itu adalah sesuatu yang niscaya. Intinya sikap toleran adalah sikap yang terbuka dan tidak 
menafikan yang lainnya. Para sahabat sangat baik sekali mempraktikkan sikap toleran. Misalnya Abu Bakar melaksanakan shalat Tahajjud setelah bangun tidur, sementara Umar bin Khattab tidak tidur dulu saat menjalankan salat Tahajjud. Para ulama terdahulu juga sangat toleran sekali. Imam Syafi'i misalnya. Bahkan, dia sampai berkata: "Kalau pendapatku benar tapi mungkin juga salah. Pendapat orang lain salah tapi mungkin juga benar."

Keenam, memahami sunnatullah dalam penciptaan. Allah menciptakan segal sesuatu melalui proses, meski dalam Al-Qur'an disebutkan kalau Allah mau maka tinggal "kun fayakun." Namun dalam beberapa hal seperti penciptaan langit dan bumi yang diciptakan dalam waktu enam masa. Pun dalam penciptaan manusia, hewan, dan tumbuhan. Semua ada tahapannya. Begitu pun Islam, orang yang bersikap moderat pasti memahami kalau ajaran-ajaran Islam itu diturunkan dan didakwahkan secara bertahap.

Pada awal-awal, Nabi Muhammad saw. berdakwah secara sembunyi-sembunyi, lalu terang-terang-terangan. Juga dalam minuman keras (khamr) misalnya. Ada empat tahapan dalam pelarangan khamr: informasi kalau kurma dan anggur itu mengandung khamr (an-Nahl: 67), informasi manfaat dan mudarat khamr (al-Baqarah: 219), larangan melaksanakan shalat saat mabuk (an-Nisa: 43), dan penetapan keharaman khamr (al-Maidah: 90). KH A Mustofa Bisri, ulama kharismatik Nahdlatul Ulama (NU), juga menegaskan kalau Islam itu moderat dan kalau tidak moderat berarti itu bukan Islam. Akan tetapi, sifat atau karakter dasar Islam yang moderat itu tertutup oleh perilaku dan sikap sebagian umat Islam yang berlebih-lebihan (ghuluw), baik yang radikal, yang fundamental, atau pun yang liberal. Bukankah sebaik-baiknya urusan adalah yang pertengahan (khoriul umuri awsathuha) ${ }^{28}$.

\section{Sikap Moderat Perspektif Muhammadiyah}

Konsep Islam moderat Muhammadiyah (wasathiyah) merujuk pada makna ummatan wasathan (QS al-Baqarah [2]: 143). Kata wasath dalam ayat tersebut berarti khiyâr (terbaik, paling sempurna) dan 'âdil (adil). Dengan demikian, makna ungkapan ummatan wasathan berarti umat terbaik dan adil, tentu dalam koridor yang luas pemaknaannya. Dalam praktiknya, Islam moderat pilihan Muhammadiyah, selalu mencari jalan tengah dalam menyelesaikan persoalan. "Perbedaan" dalam bentuk apa pun dengan sesama umat beragama diselesaikan lewat kompromi yang menjunjung

\footnotetext{
${ }^{28} \mathrm{NU}$ online diakses melalui laman, https://www.nu.or.id/post/read/93128/enam-ciri-sikap-moderatdalam-berislam, 19 Agustus 2019
} 
tinggi toleransi dan keadilan sehingga dapat diterima oleh kedua belah pihak. Melalui cara itu pula, masalah yang dihadapi dapat dipecahkan tanpa jalan kekerasan.

Dialog-dialog keagamaan yang pernah dilakukan KH.A.Dahlan bersama sejumlah kalangan termasuk dengan tokoh-tokoh non Islam; pastur dan pendeta misionaris Kristen yang mengarah pada konsep ketuhanan, tatanan yang damai, toleran, dan berkeadilan merupakan indikasi bahwa Muhammadiyah sejak awal kemunculannya ingin menawarkan model berislam secara moderat sebagai pilihan. Dan gagasan dan praktik beliau tentang moderatisme Islam juga dinilai paling kondusif di masa kini. Moderat (moderate), yang berasal dari bahasa Latin 'moderare', diartikan dengan tidak ekstrim, sedang dan bertentangan dengan sesuatu yang radikal. Ibarat pendulum pilihan moderasi itu berada diantara dua kutub ekstim yang saling berlawanan yakni satu sisinya ekstrim kanan dan kutub ekstrim kiri pada sisi yang lain. Ketika kata moderat ini digandengkan idhofahkan dengan kata Islam, ada dua makna pokok yang tidak dapat dipisahkan, karena pemisahan keduanya akan menghasilkan pemahaman yang bertolak belakang.

Pertama,Islam moderat yang dipilih Muhammadiyah harus berangkat dari keyakinan bahwa Islam adalah agama moderat. Islam merupakan moderasi atau antitesis dari ekstrimitas agama sebelumnya, di mana ada Yahudi yang sangat "membumi" dan Nasrani yang terlalu "melangit". Islam merupakan jalan tengah dari dua versi ekstrim di atas dan memadukan "kehidupan bumi" dan "kehidupan langit". Itulah makna dari ummatan wasathan (umat pertengahan, pilihan dan adil).

Kedua, moderasi Islam yang dipilih Muhammadiyah di atas harus ditindaklanjuti dalam memahami dan menjalankan Islam dengan menjauhi sikap 'tatharruf' (ekstrim). Moderasi dalam Islam bermain di antara dua kutub ekstrim, yaitu overtekstualis dan overrasionalis. Pendekatan Overtekstualis akan mengerdilkan ruang ijtihad dan rasio sehingga menghasilkan kejumudan dan pengebirian akal, yang notabene merupakan karunia terbesar Allah. Sikap ini akan menyulitkan dinamisme-interaktif Islam dengan dunia yang terus berkembang dan modern. Pendekatan over-rasionalis juga akan berbuah pahit karena akan melahirkan 'kenakalan rasio' terhadap teks dalam upaya "penyelarasan" Islam dengan dinamisme zaman. Dari rahim pendekatan semacam ini telah melahirkan liberalisme pemikiran yang dahsyat yang sering kali bukan hanya tidak sesuai dengan teks, namun juga berisi gugatan-gugatan yang tidak perlu dan hanya membuang energi.

Ketiga, Konsep Islam moderat pilihan Muhammadiyah bukan berarti sikap yang tidak berpihak kepada kebenaran serta tidak memiliki pendirian untuk menentukan 
mana yang haq dan bathil. Warga Muhammadiyah sebagai muslim moderat juga bukan orang munafik yang selalu cari aman, "plin-plan" dan memilih-milih ajaran Islam sesuai dengan kepentingannya. Muslim moderat berkeyakinan bahwa totalitas Islam merupakan agama yang selalu modern, tidak bermusuhan dengan dinamika dunia dan umat beragama lainnya. (lihat pengertian "umuruddunia" pada kitab masailul alhomsah $)^{29}$.

\section{PENUTUP}

Sebagai bagian akhir terhadap tulisan ini, terdapat 4 (empat) hal yang perlu dicatat dan disimpulkan yaitu;

Pertama; NU dan Muhammadiyah selalu menanaman nilai-nilai moderat Islam kepada masyarakat meliputi: 1) Nilai keimanan, 2) Nilai ibadah, dan 3) Nilai akhlak.

Kedua; Menjunjung tinggi nilai-nilai moderasi Islam melalui sikap toleransi terhadap sesama sebangsa setanah air dalam bentuk membudayakan tolong menolong, saling membantu dan bersikap sosial dengan baik.

Ketiga; Berkaca di sini merupakan gambaran sejarah masa lalu bahwa NU Muhammadiyah sebenarnya adalah dua organisasi masyarakat yang mempunyai sikap sangat moderat yang patut dicontoh, sehingga mewujudkan kebebasan memeluk agama adalah bahwa Islam mengayomi secara penuh hak-hak kaum dzimmi, yakni nonmuslim yang mengadakan perjanjian damai di wilayah kekuasaan umat Islam.

Keempat; Realitas masyarakat Indonesia sekarang rawan akan terjadinya potensi konflik horizontal yang disebabkan faktor agama. Namun sejatinya konflik agama biasanya tidak murni disebabkan oleh faktor agama, dapat juga terjadi akibat non agama seperti kesenjangn sosial, ekonomi, politik dan lain sebagainya. Oleh karena itu, untuk menjaga potensi konflik di butuhkan dialog dan rumusan implementatif terkait teologi wasatiyyah islam (moderasi Islam). Konsepsi dan implementasi Wasatiyyah Islam merupakan konsep utama yang terkait dengan ajaran islam dan pengalamannya untuk membentuk pribadi dan karakter muslim, konsep ini melekat dengn konsep ummatan wasathan.

${ }^{29} \mathrm{http}: / /$ www.muhammadiyah.or.id/id/news-12243-detail-moderat-dalam-bersikap-berfikir-danbertindak.html. Diakses, 19 Agustus 2019 


\section{DAFTAR PUSTAKA}

Abdurrahman Mas'ud, (2006), "Dari Haramain ke Nusantara : Jejak Intelektual Arsitek Pesantren”, Jakarta: Kencana.

Abdurrahman, Khalid. 2006. Cara Islam Mendidik Anak. Yogyakarta: ad-Dawa.

Agung, M.Jiva. 2017. Apa itu "Moderasi Islam". www.kompasiana.com. diakses tanggal 19 Agustus 2019.

Ahmad Zainul Hamid. "NU dalam Persinggungan Ideologi: Menimbang Ulang Moderasi Keislaman Nahdatul Ulama”. Afkar, Edisi No. 21 Tahun 2017.

Alwi Shihab, Membendung Arus: Respons Gerakan Muhammadiyah terhadap Penetrasi Misi Kristen di Indonesia, Jakarta: Mizan, 1998.

Departemen Agama RI, Moderasi Islam, Jakarta: Lajnah Pentashihan Mushaf AlQur'an, 2012

Kamus Besar Bahasa Indonesia Versi Online. https://www.kbbi.web.id. diakses tanggal 19 Agustus 2019.

M. Hilaly Basya, "Menelusuri Artikulasi Islam Moderat di Indonesia", http://www.madinask.com. diakses tanggal 19 Agustus 2019.

Muhajir, Afifudin. 2018. Membangun Nalar Islam Moderat Kajian Metodologis. Situbondo: Tanwirul Afkar.

Muhammad Mihanna, Al-Irhāo wa Azmat al-Qānūn al-Dauly al- Mu'āshir, dalam AlIslām fi Muwājahat al-Irhābi, Cairo: Rābithah al-Jāmi'at al- Islāmiyah, 2003.

Mujamil Qomar, NU Liberal; Dari Tradisionalisme Ahlusunnah ke Universalisme Islam, Bandung: Mizan, 2002.

Muhammadiyah online, http://www.muhammadiyah.or.id/id/ detail moderat dalam bersikap berfikir dan bertindak.html. Diakses, 19 Agustus 2019.

NU online diakses melalui laman, https://www.nu.or.id. Enam ciri sikap moderat dalam berislam, 19 Agustus 2019.

Nurul Faiqah, Toni Pransiska, Radikalisme Islam vs moderasi Islam: Upaya membangun wajah Islam indonesia yang damai, Al Fikra, Jurnal Keislaman, Vol 17 No 1 Januari-Juni 2018.

Undang-undang RI No. 20 Tahun 2003 tentang Sistem Pendidikan Nasional. 2006. Jakarta: Sinar Grafika.

Zamakhsyari Dhofier, Tradisi Pesantren; Studi Tentang Pandangan Hidup Kiai, Jakarta: LP3ES, 1994.

Zuhairi Misrawi,Hadratussyaikh Hasyim Asy'ari Moderasi, Keutamaan, dan Kebangsaan, Jakarta: PT Kompas Media Nusantara, 2010 